\title{
Nurses' Knowledge and Attitude Regarding Evidence-Based Practice: An Integrative Review
}

\author{
Ayat Mohamed Ahmed Zammar \\ General Directorate of Health Affairs in Riyadh Region, Riyadh, Saudi Arabia \\ Email: zammarawrad@gmail.com
}

How to cite this paper: Zammar, A.M.A. (2022) Nurses' Knowledge and Attitude Regarding Evidence-Based Practice: An Integrative Review. Open Journal of Nursing, 12, 103-112.

https://doi.org/10.4236/ojn.2022.122007

Received: December 18, 2021

Accepted: February 15, 2022

Published: February 18, 2022

Copyright (อ 2022 by author(s) and Scientific Research Publishing Inc. This work is licensed under the Creative Commons Attribution International License (CC BY 4.0).

http://creativecommons.org/licenses/by/4.0/

\section{(c) (i) Open Access}

\begin{abstract}
Background: As a result of its influence on nurses' knowledge and practice, evidence-based practice (EBP) has gained prominence in the nursing profession. Therefore, evidence-based practice (EBP) is increasingly acknowledged as a critical component of improving the quality of healthcare and nursing care services, as well as achieving patient care excellence. Aim: One of the primary objectives of this review is to consolidate the existing research on nurses' understanding of evidence-based practice, attitudes toward it, and practices related to it. Methods: The following databases from 2012 to 2021 have been searched such as: Cochrane Collaboration, MEDLINE, AVOID, CINAHL, EMBASE, Science Direct, ASSIA, Web of Science, Scopus, PubMed and JSTOR. Only cohort, case-control and randomized controlled trials studies with full text in English were eligible. Results: Only eight articles were found to meet the inclusion criteria out of 2155 total articles after the exclusion criteria were applied. The majority of these eight researches discovered a favourable attitude about EBP as well as a low level of expertise. Conclusion: The majority of nurses have a good attitude toward their job, but most are uninformed of the significance of EBP in their profession. In order to recognize and compare the components that may impact knowledge, attitude, and practices of EBP throughout the world in order to discover similarities that may assist global strategies for the transfer of research results to nursing, additional research on this topic is required to recognize and compare the components that may impact knowledge, attitude, and practices of EBP throughout the world in order to discover similarities that may assist global strategies for the transfer of research results to nursing.
\end{abstract}

\section{Keywords}

Knowledge, Attitude, Evidence-Based Practice 


\section{Background}

EBP is a term that was used to represent a systematic approach to improving healthcare and clinical decision-making that is based on the most recent research evidence available at the time. When basing practice on research and evidence, it is critical to convey and accept the evidence; yet, nurses frequently depend on tradition or intuitive processes as the explanation for treatments [1]. A consequence is that nursing interventions may be dictated by what the nurse has already learnt via formal education and practical experience; as a result, differences in practice will be found that are not supported by logic [2].

Clinical decision-making should be informed by the most recent research information available, which is referred to as "evidence-based practice." To address evolving clinical difficulties, it may be employed as a problem-solving strategy and as a decision-making framework that takes into consideration the patient's values as well as the practitioner's own opinions. It may be used to offer solutions to new clinical problems as they arise in the field [2]. As a result of its influence on nurses' knowledge and practice, EBP has gained prominence in the nursing profession. Therefore, EBP is increasingly acknowledged as a critical component of improving the quality of healthcare and nursing care services, as well as achieving patient care excellence. As a result, it is widely regarded as an important component of healthcare quality, particularly in the United States [3].

Nurses' clinical talents and patient preferences must be combined with the best available clinical data from systematic research, as well as readily available resources, in order to conduct EBP [4]. When it comes to using EBP, nurses must possess a variety of abilities, including the ability to perform literature searches and evaluate evidence [3]. Researchers have discovered that nurses' knowledge, attitudes, and beliefs regarding EBP can have a considerable influence on the amount to which EBP is implemented in the clinical setting [5]

It is common for people to believe that evidence-based practice means that intuition and personal experience are no longer valid, although this is not always the case. Several studies, including one conducted in Saudi Arabia to examine nurses' knowledge, attitude, and practice toward evidence-based practice, found that the nurses lacked the necessary knowledge and practice of evidence-based practice, and that they lacked the necessary attitude and practice [6].

Different factors related to individual, professional, and organizational characteristics are perceived as barriers to translating evidence-based practice into various clinical applications among nurses, including a lack of access to electronic databases and expensive scientific articles, a lack of knowledge about how to handle those databases and critically appraise research results, a lack of time for documentary research, and the difficulty of transferring research results into practicum settings [7].

In their study of EBP among nurses, researchers reached the conclusion that the most major obstacle to its adoption is a lack of time to conduct research, as well as to understand and analyze research data [8] [9]. 


\section{Aim}

The purpose of this integrative review is to synthesise existing material regarding EBP among nurses, using the integrative review approach developed by Whittemore and Knafl [10].

\section{Methods}

As a nursing resource, an integrated review is a systematic approach to acquiring scientific knowledge that is then evaluated and summarized. It's comparable to what you'd find in a systematic review. Because it allows for the inclusion of primary research that uses a variety of methodological approaches and study designs for analysis, rather than only randomized clinical trials as the systematic review suggests, this approach differs from the traditional systematic review [10]. Among the components of the thorough evaluation are a critical examination of the data and a determination of the current state of knowledge about the subject of interest [11].

Each of the six processes of the current review was completed: formulation of a research topic for the review, search for primary studies in the literature, data extraction, assessment of primary studies, interpretation of results, and presentation of the review results [10]. The issue that guided the construction of the review was: What Knowledge, Attitudes, and Practices are prevalent in the application of EBP among care nurses in hospitals? The review was conducted to answer this question.

\section{Problem Identification}

EBP has been a major emphasis throughout the world for many years; both the World Health Organization (WHO) and the European Commission emphasize that health and social services should be based on the most up-to-date research findings that are currently available [12]. It is vital when it comes to healthcare that evidence-based practice is followed. Current nursing practice may be criticized for failing to take use of the availability of current evidence in order to provide healthcare based on such data and to assess the effectiveness of nursing treatments [12].

As a result, there will be a lack of implementation of such an issue in Saudi Arabia, which will result in the provision of nursing care that is not based on current evidence, which will ultimately result in a worsening of the overall quality of healthcare that is provided to all patients in the country. It is also possible that failure to adopt EBP may lead to an increase in the complications of some diseases as a consequence of a lack of evidence in the care provided, which might result in an increase in the financial costs of the Saudi healthcare system as well.

Evidence-practice gaps also result in underutilization of proven therapies and overutilization of erroneous treatments, as previously stated. As a result, it is vital to incorporate nurses in evidence-based practice (EBP) and to strengthen the infrastructure for the provision of EBP in order to increase the scientific rigor of nursing care and to modify the quality of nursing care. Accordingly, a better 
understanding of nurses' beliefs about evidence-based practice, as well as whether and how they use it, is essential for increasing its use and providing safe, high-quality health care for all patients [8].

\section{Literature Search}

All English-language studies published between 2006 and 2019 were found using the electronic databases Cochrane Collaboration, MEDLINE, CINAHL, AVOID, EMBASE (Science Direct), Science Direct ASSIA (Web of Science), Scopus (Scopus), PubMed (JSTOR), and JSTOR, which were searched between 2012 and 2019. The search was conducted using the keywords evidence-based practice, knowledgebased practice, attitude-based practice, nurses, Evidence-Based Nursing, Nursing, Evidence-Based, connected with Evidence-Based Practice and [Nursing research], as well as [Attitudes toward research] and [Barriers to research] in order to find relevant results. There were several terms that were utilized in regard to LILACS, including [Evidence-Based Nursing] or [Evidence-Based Clinical Practice] in conjunction with and [Nursing Research], and [Attitudes], and [Barriers].

Upon further investigation, it was discovered that 182 of the 220 research articles initially retrieved using the search parameters were irrelevant, and 125 were judged to be duplicates based on the titles of the research papers. In the following step, the abstracts of these 59 papers were reviewed, and 52 papers were chosen to be read in their entirety. After reading all of the submissions, 29 were eliminated from consideration.

The remaining 20 were thoroughly read and reviewed for quality assurance. Six articles were discarded after reading the complete text, and six papers were rejected based on the quality of the writing in the papers themselves. It was decided to include them in the evaluation after thoroughly reading the whole text of eight books (Figure 1). It was only primary empirical research publications that met the study's inclusion requirements, which included those that had been published in English, were relevant to nurses, had the entire text available, and were published in a peer-reviewed journal.

\section{Results}

Table 1 illustrates the findings of included studies in this integrative review. The main aim, design, and measures are also included in the table.

Table 1. Main findings of the included studies in the current integrative review.

\begin{tabular}{|c|c|c|c|c|c|}
\hline Author/year & Aim & Design & Sample & Measure & Results \\
\hline $\begin{array}{c}\text { AbuRuz et al. } \\
\text { (2017) [3] }\end{array}$ & $\begin{array}{l}\text { To examine the } \\
\text { knowledge, attitudes, } \\
\text { and practice of Jordanian } \\
\text { nurses in the area of } \\
\text { evidence-based practice } \\
\text { at seven major hospitals } \\
\text { in Jordan. }\end{array}$ & Cross-sectional & 500 & Questionnaire & $\begin{array}{l}\text { The attitudes toward evidence-based practice } \\
\text { were determined to be the most popular, } \\
\text { followed by attitudes toward knowledge and } \\
\text { skills, and finally attitudes toward practice and } \\
\text { implementation. Nurses that are female undertake } \\
\text { less research and have a more negative attitude } \\
\text { toward their jobs, and they are less educated about } \\
\text { research processes than nurses who are male. }\end{array}$ \\
\hline
\end{tabular}


Ez elarab et al. knowledge, attitude, and (2012) [6] practice (KAP) among nurses in Saudi Arabia.
To assess nurses'

According to nurses' awareness of terminology connected with EBP, there is no statistically significant variation in knowledge based on their educational level or nationality. Also found was no difference in nurses' attitudes toward evidencebased practice and practice of EBP between those who had a bachelor's degree and those who had obtained a certificate, and no difference in knowledge-related EBP between Saudi and non-Saudi nurses. The percentage of excellent practices in EBP reported by non-Saudi nurses was much higher (60.5 percent), with the majority of their overall self-reported practice being always, compared to 39.5 percent of Saudi nurses.

Evidence-based practice (EBP) was seen positively by clinical nurses, but their comprehension of EBP, organizational preparation, and competence to implement EBP were deemed inadequate. Researchers discovered that EBP practitioners' knowledge, attitudes, and organizational

Yoo et al. should were assessed, and (2019) [13] the elements that Cross-sectional 521 influence EBP

implementation should be identified in order to successfully establish EBP among clinical nurses.
To determine the attitudes, skills, and

Tolera and Hui sources of information of

(2017) [14] $\begin{gathered}\text { registered nurses workin } \\ \text { in selected teaching }\end{gathered}$ hospitals in China about the application of EBP.

To assess the EBP competency of Spanish and Latin-American Pérez-Campos nurses, as well as the et al. (2014) effect of sociodemographic and [15] professional characteristics, the researchers conducted a study.
Cross-sectional 366

Cross-sectional

314 scale ranging from 1 to 7 . According to the findings of the study, characteristics linked with preparation were all substantially associated with
their ability to apply the practice of EBP. In the final model, it was discovered that EBP knowledge and organizational preparation were significant predictors of EBP implementation, with the model accounting for 22.2 percent of the variation in EBP implementation.

Nurses were generally enthusiastic about the use of evidence-based practice in their clinical practice, according to the survey results. In

Questionnaire contrast, it was discovered that both the degree of ability in completing various EBP tasks and in utilizing information resources to support daily care practice were insufficient.

A score of 5.02 out of 7 was assigned to EBP on a professional category, country of employment, evaluation of practice environment, and participation in research activities.

The mean of all EBP values was 4.24 , which was the highest possible score. Although the attitude
EBP in traditional

Chinese nursing

Zhou et al. profession is being (2016) [16] studied to determine nurses' attitudes,

knowledge, and practice on EBP.
Multiple institutional cross-sectional component received the highest marks, the knowledge component received the second highest, and the practice component received the lowest marks. RNs with more years of experience had a greater grasp of EBP than their less experienced counterparts. In addition, nurses who were experiencing increasing job stress reported having fewer favorable opinions toward their jobs. 


\section{Continued}

Al-Busaidi et al. (2019) [17]
To investigate nurses' knowledge, practice, and attitudes about evidence-based practice $(\mathrm{EBP})$ in Oman.
Multiinstitutional cross-sectional study
Those with positive attitudes toward EBP were found to be the most prevalent, followed by those with knowledge and practice. According to the findings, there is a statistically significant positive relationship between the total number of years of nursing experience and the mean scores in knowledge, practice, and attitudes. There was no statistically significant difference in EBP ratings across the three clinical settings when comparing the three clinical settings.

When it came to mean attitude ratings per item, there was no statistically significant difference between staff nurses and nurse leaders, suggesting that nurses had good attitudes toward evidence-

Al-Maskari \& of Omani nurses toward evidence-based practice Patterson (EBP), as well as their (2018) [18] assessments of the Cross-sectional 260 challenges to and facilitators of EBP adoption in Oman. based practice. While nurse leaders outperformed staff nurses in the subsections on obstacles to changing practice and obtaining and reviewing evidence, they scored lower than staff nurses in the subsection on facilitators of changing practice.

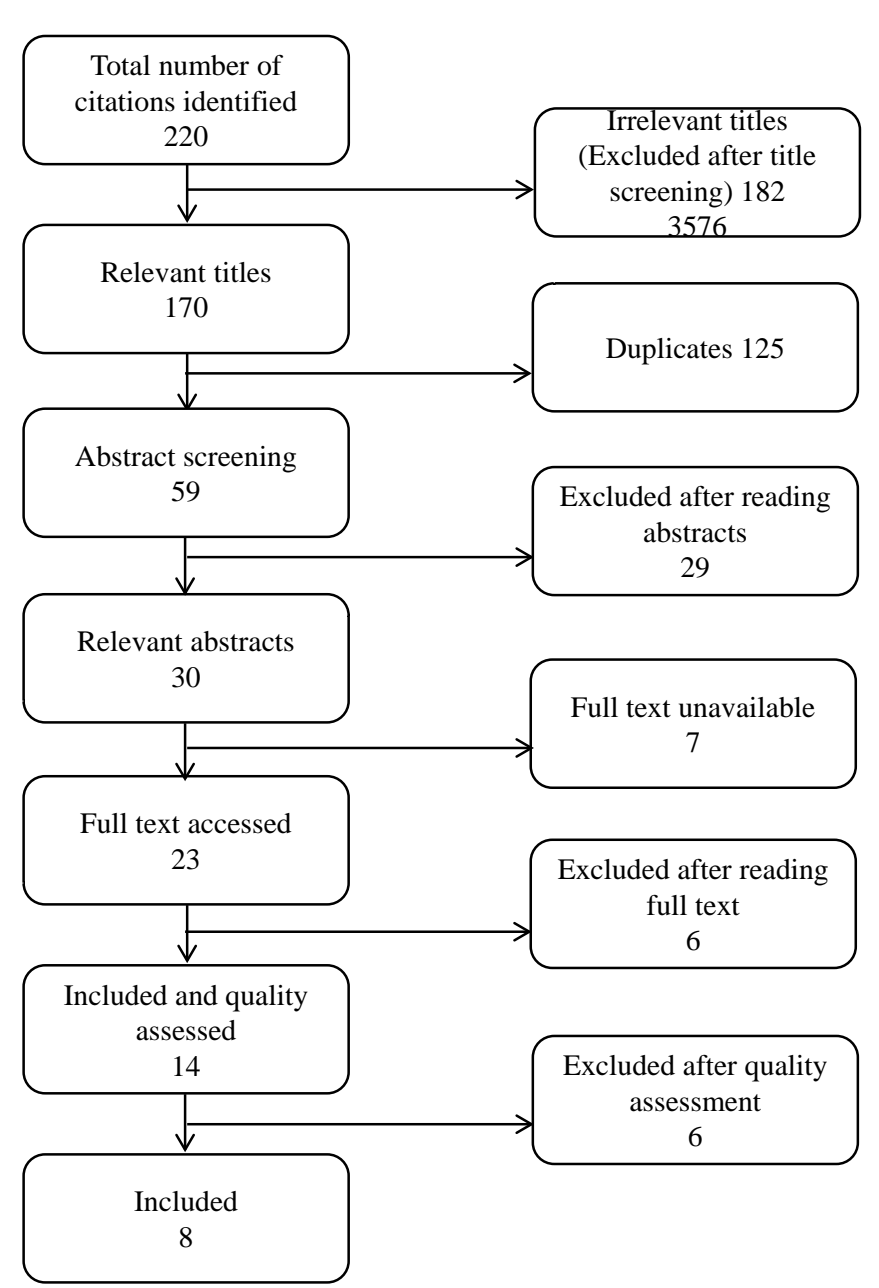

Figure 1. Flow diagram of the process of identifying and including references for the review. 


\section{Discussion}

Overall, the findings of the research included in this review revealed that nurses had good attitudes toward EBP, despite the fact that they possessed little understanding of the topic. Researchers have identified nurses' lack of knowledge of research and statistical processes, as well as their lack of education and experience in research and statistics, as significant factors in their poor performance in EBP [19] [20]. As a result of this research, nurses demonstrate a general deficiency in clinical inquiry production, access to evidence, critical evaluation, and practical application, all of which are crucial to the profession.

Nurses must be aware of continually developing scientific information and have the ability to make critical judgements about such research, according to EBP professionals, in order to carry out EBP procedures [19]. Individual attempts by nurses to increase their EBP competence, on the other hand, are unlikely to yield significant results; as a result, organizational assistance is required [20]. According to the findings of several previous studies, appropriate learning environments and amenities are required for the effective implementation of EBP in nursing organizations [19] [21].

Organizations require a knowledge management system, information systems, and databases that are linked to nursing in order to obtain the information needed for clinical decision-making as quickly and efficiently as possible. To improve nurses' EBP knowledge, an educational method that encourages organizational team learning and continual learning opportunities might be implemented. A recent study conducted by [19] stressed the need of employing a learning framework as an alternative to standard lecture methodologies for imparting knowledge. It is recommended that, rather than a lecture-style teaching program, a workshop-based educational program that combines debates and brainstorming sessions be implemented at the ward level in order to achieve this goal. Developing targeted educational initiatives, such as journal clubs on wards that focus on clinical concerns that are specific to each ward, is also crucial to success. A learning organization with an EBP preceptor or a mentorship program for EBP practitioners may also be taken into consideration. It is believed that including the EBP concept into the preceptor training program at the organizational level will aid in the development of knowledge and positive attitudes about EBP among preceptors [21].

Additionally, encouraging nurses to attend the conference and establishing incentives for them to submit their findings at the conference will be crucial success factors. A training program for human resources, such as EBP mentors, would be required in order for them to function as EBP facilitators and EBP Champions on the ward. As part of the design of EBP education programs, it is necessary to establish and implement a hands-on education component in collaboration with librarians, so that practical performance may now be carried out outside of the EBP concept, or the importance of practical performance should be stressed. In the study by [21] intense training programs such as a four-hour 
workshop each day, computer-based training consisting of three modules that each take 15 - 20 minutes to complete, and team-based training programs of 2 3 hours per week were shown to be beneficial in enhancing EBP knowledge. The creation of EBP-related scenarios for each clinical condition, as well as the implementation of a simulation-based EBP training program, would be two options.

Positivity toward evidence-based practice (EBP) serves as a good basis for designing suitable nursing techniques to improve the implementation of this practice. Nursing attitudes toward evidence-based practice (EBP) and knowledge of its utility in clinical settings are most likely to have been influenced by the Hawthorne observer effect, as well as regular exposure to EBP workshops and training programs, according to the findings [22] [23].

\section{Limitations}

The research covered in this study has been published for more than five years, and it is vital to inspire fresh research to determine whether there have been any changes in hospital nurses' knowledge, attitudes, and actions in EBP during that time period. Alternatively, the most significant health (PubMed) and nursing (CINAHL) databases were selected as a backup option. As a result of the limited number of studies included in this review, it is possible that there will be gaps in the scientific production of findings on knowledge, attitudes, and behaviors in the implementation of EBP among nursing assistants working in hospitals, as only cross-sectional studies were included in this review. Given the small number of studies included in this evaluation, this may not be a major source of concern.

\section{Conclusion}

Despite the fact that hospital nurses have positive attitudes toward evidencebased practice and believe that research contributes to nurses' advancement, developing an evidence-driven role from scientific research is a global challenge; this is especially true when considering that the most frequently used terms as sources of evidence by hospital nurses are: personal experience and local care protocols. More research on this topic is recommended in order to identify and compare the factors that may influence EBP knowledge, attitude, and practices around the world in order to identify similarities that can support global strategies for the transfer of research results to the nursing side of the bed hospital.

\section{Conflicts of Interest}

The author declares no conflicts of interest regarding the publication of this paper.

\section{References}

[1] Fisher, C., Cusack, G., Cox, K., Feigenbaum, K. and Wallen, G.R. (2016) Developing 
Competency to Sustain Evidence-Based Practice. The Journal of Nursing Administration, 46, 581-585. https://doi.org/10.1097/NNA.0000000000000408

[2] Melnyk, B.M., Gallagher, L., Long, L.E. and Fineout, E. (2014) The Establishment of Evidence-Based Practice Competencies for Practicing Registered Nurses and Advanced Practice Nurses in Real World Clinical Settings: Proficiencies to Improve Healthcare Quality, Reliability, Patient Outcomes, and Costs. Worldviews on Evidence-Based Nursing, 11, 5-15. https://doi.org/10.1111/wvn.12021

[3] AbuRuz, M., Hayeah, H., Al-Dweik, G. and Al-Akash, H. (2017) Knowledge, Attitudes, and Practice about Evidence-Based Practice: A Jordanian Study. Health Science Journals, 11, 1-8. https://doi.org/10.21767/1791-809X.1000489

[4] Xie, H.T., Zhou, Z.Y., Xu, C., Ong, S. and Govindasamy, A. (2017) Nurses' Attitudes towards Research and Evidence-Based Practice: Perspectives from Psychiatric Setting. JOJ Nurse Health Care, 3, Article ID: 555624.

[5] Ammouri, A.A., Raddaha, A.A., Dsouza, P., Geethakrishnan, R., Noronha, J.A., et al. (2014) Evidence-Based Practice: Knowledge, Attitudes, Practice and Perceived Barriers among Nurses in Oman. Sultan Qaboos University Medical Journal, 14, e537.

[6] Ez elarab, H., El Salam, S., Behalik, S. and Eltayeb, H. (2012) Nurses, Practice, Knowledge and Attitude towards Evidence-Based Practice at Yanbu General Hospital Kingdom of Saudi Arabia. Life Science Journal, 9, 1062-1071.

[7] Baird, L.M. and Miller, T. (2015) Factors Influencing Evidence-Based Practice for Community Nurses. British Journal of Community Nursing, 20, 233-242.

https://doi.org/10.12968/bjcn.2015.20.5.233

[8] Gomes Pereira, R.P., da Silva Peixoto de Oliveira Cardoso, M.J. and Correia dos Santos Cardoso Martins, M.A. (2012) Attitudes and Barriers to Evidence-Based Nursing Practice in a Community Context. Dominio de Enfermagem, 3, 55-62.

[9] Mallion, J. and Brooke, J. (2016) Community- and Hospital-Based Nurses' Implementation of Evidence-Based Practice: Are There Any Differences? British Journal of Community Nursing, 21, 148-154. https://doi.org/10.12968/bjcn.2016.21.3.148

[10] Whittemore, R. and Knafl, K. (2005) The Integrative Review: Update Methodology. Journal of Advanced Nursing, 52, 546-553. https://doi.org/10.1111/j.1365-2648.2005.03621.x

[11] Mendes, K.D.S., Silveira, R.C.C.P. and Galvão, C.M. (2008) Revisão integrativa: Método de pesquisa para a incorporação de evidências na saúde e na enfermagem. Texto \& Contexto Enfermagem, 17, 758-764. https://doi.org/10.1590/S0104-07072008000400018

[12] Stokke, K., Olsen, N.R., Espehaug, B., et al. (2014) Evidence Based Practice Beliefs and Implementation among Nurses: A Cross-Sectional Study. BMC Nursing, 13, Article No. 8. https://doi.org/10.1186/1472-6955-13-8

[13] Yoo, J.Y., Kim, J.H., Kim, J.S., Kim, H.L. and Ki, J.S. (2019) Clinical Nurses' Beliefs, Knowledge, Organizational Readiness and Level of Implementation of EvidenceBased Practice: The First Step to Creating an Evidence-Based Practice Culture. PLoS $O N E, 14$, e0226742. https://doi.org/10.1371/journal.pone.0226742

[14] Tolera, B.D. and Hui, F. (2017) Assessment of Attitudes, Skills and Source of Knowledge on Utilization of EBP among Registered Nurses in Xiangya Hospital of Central South University, Changsha, China. American Journal of Nursing Science, 6, 99-112. https://doi.org/10.11648/j.ajns.20170602.14

[15] Pérez-Campos, M.A., Sánchez-García, I. and Pancorbo-Hidalgo, P.L. (2014) Knowledge, Attitude and Use of Evidence-Based Practice among Nurses Active on the 
Internet. Investigación y Educación en Enfermería, 32, 451-460.

https://doi.org/10.17533/udea.iee.v32n3a10

[16] Zhou, F., Hao, Y., Guo, H. and Liu, H. (2016) Attitude, Knowledge, and Practice on Evidence-Based Nursing among Registered Nurses in Traditional Chinese Medicine Hospitals: A Multiple Center Cross-Sectional Survey in China. Evidence-Based Complementary and Alternative Medicine: eCAM, 2016, Article ID: 5478086.

https://doi.org/10.1155/2016/5478086

[17] Al-Busaidi, I.S., Al Suleimani, S.Z., Dupo, J.U., Al Sulaimi, N.K. and Nair, V.G. (2019) Nurses' Knowledge, Attitudes, and Implementation of Evidence-Based Practice in Oman: A Multi-Institutional, Cross-Sectional Study. Oman Medical Journal, 34, 521-527. https://doi.org/10.5001/omj.2019.95

[18] Al-Maskari, M.A. and Patterson, B.J. (2018) Attitudes towards and Perceptions Regarding the Implementation of Evidence-Based Practice among Omani Nurses. Sultan Qaboos University Medical Journal, 18, e344-e349.

https://doi.org/10.18295/squmj.2018.18.03.013

[19] Cho, M.S., Cho, Y.A., Song, M.R., Kim, M.K. and Cha, S.K. (2013) Development of a Program to Facilitate Evidence-Based Practice Based on the Transtheoretical Model. Korean Journal of Adult Nursing, 25, 136-147. https://doi.org/10.7475/kjan.2013.25.2.136

[20] Park, H.Y. and Jang, K.S. (2016) Structural Model of Evidence-Based Practice Implementation among Clinical Nurses. Journal of Korean Academy of Nursing, 46, 697-709. https://doi.org/10.4040/jkan.2016.46.5.697

[21] Nam, A.R.N., Lee, E.H., Park, J.O., Ki, E.J., Nam, S.M. and Park, M.M. (2017) Effects of an Evidence-Based Practice (EBP) Education Program on EBP Practice Readiness and EBP Decision Making in Clinical Nurses. Journal of Korean Academy of Nursing Administration, 23, 239-248. https://doi.org/10.11111/jkana.2017.23.3.239

[22] Williamson, K.M., Almaskari, M., Lester, Z. and Maguire, D. (2015) Utilization of Evidence-Based Practice Knowledge, Attitude, and Skill of Clinical Nurses in the Planning of Professional Development Programming. Journal for Nurses in Professional Development, 31, 73-80. https://doi.org/10.1097/NND.0000000000000140

[23] Melnyk, B.M. and Fineout-Overholt, E. (2010) Evidence-Based Practice in Nursing \& Healthcare: A Guide to Best Practice. 2nd Edition, Lippincott Williams \& Wilkins, Philadelphia, 3-39. 